\title{
A CLASS OF EXPONENTIAL INEQUALITIES
}

\author{
JONATHAN BORWEIN AND ROLAND GIRGENSOHN
}

Abstract. We prove that for reals $x_{i}$ with $\sum x_{i} \geqslant 0$, the estimate $\sum x_{i} e^{x_{i}} \geqslant \frac{C_{N}}{N} \sum x_{i}^{2}$ holds, where $C_{N}=\max \{2, e(1-1 / N)\}$. We also prove analogues for the 1-norm and for Lebesgueintegrable functions.

Mathematics subject classification (2000): 26D15.

Key words and phrases: Inequalities, exponential function, $p$-norm.

\section{REFERENCES}

[1] J. M. BorweIn, A. S. LEWIS, Convex Analysis and Nonlinear Optimization, CMS Books in Mathematics, Volume 3, Springer-Verlag, New York, 2000.

[2] B. Kostant, P. W. MichoR, The generalized Cayley map from an algebraic group to its Lie algebra, Preprint, math. RT/0109066

[3] D. S. Mitrinović, J. E. PeČARIĆ, A. M. FinK, Classical and New Inequalities in Analysis, Kluwer, 1993.

[4] K. R. StromberG, An Introduction to Classical Real Analysis, Wadsworth, 1981. 